\title{
Acute Infectious Endophthalmitis After Cataract Surgery: Epidemiological Characteristics, Risk Factors and Incidence Trends, 2008-2019
}

This article was published in the following Dove Press journal: Infection and Drug Resistance

\author{
Jiajun Sun ${ }^{1,2}$ \\ Zhen Guo ${ }^{1,2}$ \\ Honglei $\mathrm{Li}^{1,2}$ \\ Baoxia Yang ${ }^{1,2}$ \\ Xiaoming $\mathrm{Wu}^{\mathrm{l}, 2}$ \\ 'Qingdao Eye Hospital of Shandong \\ First Medical University, Qingdao, \\ 26607I, People's Republic of China; \\ ${ }^{2}$ State Key Laboratory Cultivation Base, \\ Shandong Provincial Key Laboratory of \\ Ophthalmology, Shandong Eye Institute, \\ Shandong First Medical University and \\ Shandong Academy of Medical Sciences, \\ Qingdao, 26607I, People's Republic of \\ China
}

Correspondence: Xiaoming Wu State Key Laboratory Cultivation Base, Shandong Provincial Key Laboratory of Ophthalmology, Shandong Eye Institute, Shandong First Medical University and Shandong Academy of Medical Sciences, Qingdao, 26607I, People's Republic of China

Tel +860532-87610668

Email wuxiaominglmm@I26.com
Objective: Intended to investigate the epidemiological characteristics, risk factors and incidence trend of endophthalmitis after cataract surgery in recent 12 years.

Methods: A retrospective study was conducted on the patients who underwent cataract surgery in Qingdao Eye Hospital from January 1, 2008, to December 31, 2019, including age, sex, history of diabetes, intraoperative operation and complications. In addition, the related risk factors and incidence trend of acute infective endophthalmitis were analyzed. The incidence of endophthalmitis and its related factors were analyzed by univariate and multivariate logistic regression analysis.

Results: A total of 55,612 cases of cataract surgery were performed in our hospital in 12 years, and 42 cases of acute infective endophthalmitis occurred (the incidence rate was $0.076 \%$ ). The average occurrence time was 10.57 days \pm 11.17 , with eye pain as the main complaint and anterior chamber fibrin exudation as the main clinical manifestation. In addition, there were eight cases of anterior chamber hypopyon and 18 cases of vitreous reaction, the results of anterior aqueous humor or vitreous fluid culture in 10 patients were positive. Univariate analysis showed that intraoperative rupture of posterior capsule, non-use of antibiotics and non-use of behind-thelens washout were the risk factors of infectious endophthalmitis after cataract surgery $(\mathrm{P}=0.032$, $\mathrm{P}=0.000, \mathrm{P}=0.000$ ). Besides, multivariate logistic regression analysis showed that intraoperative rupture of posterior capsule was the main risk factor.

Conclusion: The occurrence of endophthalmitis after cataract surgery is mainly related to intraoperative rupture of posterior capsule, absence of antibiotics and behind-the-lens washout. In addition, the incidence of endophthalmitis after cataract surgery decreased during the past 12 years. Keywords: cataract, postoperative endophthalmitis, incidence rate, pathogenic factors

As one of the most serious complications after cataract surgery, endophthalmitis can cause rapid damage to visual function and even blindness in severe cases. The incidence of endophthalmitis in developed countries is $0.012 \%-0.053 \%$ and the incidence of endophthalmitis in China in 2017 is $0.033 \%-0.11 \% .^{1-5}$ In 2020 , we analyzed the incidence rate of endophthalmitis in 55,612 patients after cataract surgery in our hospital in the past 12 years. We found that there were some characteristics in the incidence and influencing factors of endophthalmitis in our hospital, so as to guide clinical work.

\section{Patients and Methods}

The patients who underwent cataract extraction combined with intraocular lens implantation in Qingdao Eye Hospital from January 1, 2008, to December 31, 
2019, were studied retrospectively. The study was conducted in accordance with the Declaration of Helsinki and approved by the institutional review board of Shandong Eye Institute. Written informed consent was obtained from all the studied subjects for sample collection and subsequent analyses. In addition, the general data of the patients were recorded and the characteristics of infectious endophthalmitis after cataract surgery in the 12 years were analyzed. Inclusion criteria were as follows: clinicalor laboratory-diagnosed infective endophthalmitis occurred within 42 days after phacoemulsification or small incision extracapsular extraction combined with primary intraocular lens implantation. Exclusion criteria: cataract combined with other ophthalmic surgery (such as anti-glaucoma surgery, corneal transplantation, vitreous related surgery, etc.); patients with a history of uveitis; cataract patients with penetrating injury; and congenital cataract patients.

Clinical examination: the general data, basic diseases, surgical methods and intraoperative complications of the selected patients were collected. In addition, the symptoms, signs, visual acuity, intraocular pressure, time of endophthalmitis after cataract surgery, laboratory culture results, treatment and prognosis of patients with endophthalmitis were observed.

Clinical diagnosis: There are no obvious causes of eye pain, decreased vision, anterior chamber inflammation (anterior chamber reaction or flare, obvious cells, exudation, hypopyon, etc.), or significant vitreous inflammation after cataract surgery. In addition, patients with noninfectious uveitis, anterior segment toxic reaction syndrome or other intraocular inflammation with definite causes were excluded. Laboratory diagnosis: Patients with positive microbial culture of anterior aqueous humor or vitreous were patients with pathogenic bacteria. Once endophthalmitis was suspected, an emergency plan was immediately initiated by a consultation team, including senior experts specializing in cataract, vitreoretinal surgery, and hospital-acquired infection control.

According to the consensus of experts on the treatment of acute bacterial endophthalmitis after cataract surgery in China and the guiding principles abroad, a phased treatment scheme was adopted according to the severity of the disease. Patients with mild inflammation in the anterior chamber and no hypopyon in the anterior chamber were treated with eye drops and systemic antibiotics. Severe inflammatory reaction in the anterior chamber, with or without hypopyon and vitreous inflammation, was treated with antibiotic anterior chamber lavage or combined with vitreous injection of antibiotics. Severe anterior chamber reactions, with severe vitreous inflammation or vitreous suppuration, were conducted with antibiotic anterior chamber lavage combined with vitreous surgery.

\section{Statistical Analysis}

All statistical analyses were performed using SPSS 22.0 statistical software (SPSS, Inc., Chicago, IL). The incidence and related factors of endophthalmitis were analyzed by univariate analysis (chi-square test or Fisher exact probability test, $\mathrm{P}<0.05$ indicated statistical significance) and multivariate analysis (logistic regression analysis). Besides, the measurement data (age and visual acuity) were expressed as mean \pm standard deviation. $\mathrm{P}<0.05$ was used as the standard of statistical difference.

\section{Results}

A total of 55,612 cases of cataract extraction combined with intraocular lens implantation were performed in our hospital in the past 12 years, including 22,679 males and 32,933 females, and aged from 20 to 102 . In addition, there were 18,147 elderly patients over 75 years old, 10,306 patients with diabetes and 371 patients with unplanned posterior capsule rupture during the operation.

Changes in the amount of cataract surgery and the incidence of postoperative endophthalmitis: 42 had acute infective endophthalmitis $(0.076 \%)$ among the 55,612 patients undergoing cataract surgery, including 15 males and 27 females, aged from 27 to 85 years, and with an average age of $64.3 \pm 9.04$ years. The distribution of endophthalmitis in different months was shown in Figure 1. The cases of cataract surgery in the past 12 years were divided into three stages according to the year. As a result, it showed that the amount of cataract extraction combined with intraocular lens implantation in our hospital increased year by year from January 1, 2008, to December 31, 2019. In addition, the incidence of infectious endophthalmitis after cataract surgery decreased. The changing trend is shown in Figure 2.

\section{Analysis of Factors Related to Endophthalmitis}

Statistics and correlation analysis on the factors such as sex, age, history of diabetes, operative complications, use of antibiotics in surgical perfusion solution and behind-thelens washout and so on were conducted. As a result, it showed that the incidence of intraoperative posterior capsule 


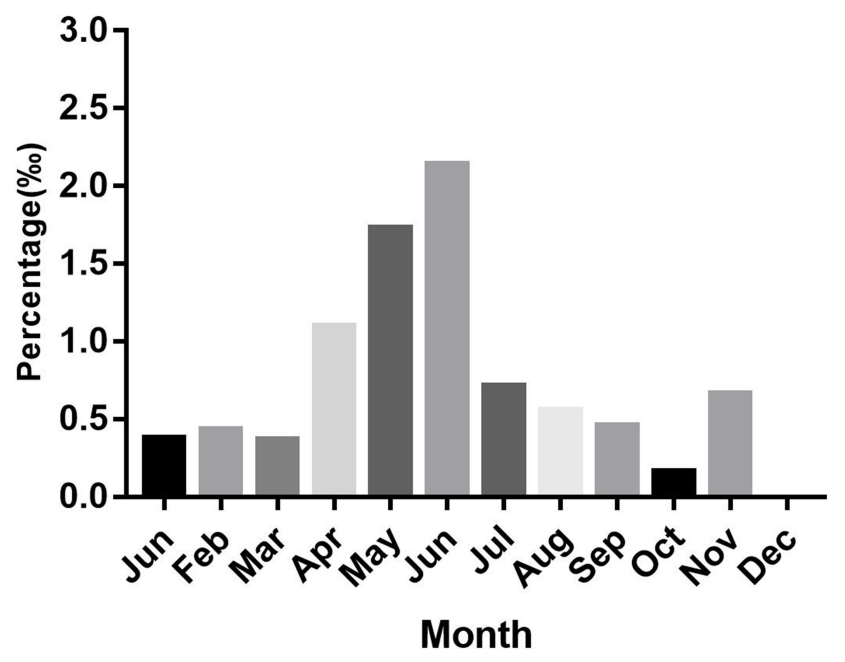

Figure I Annual distribution of endophthalmitis after cataract surgery.

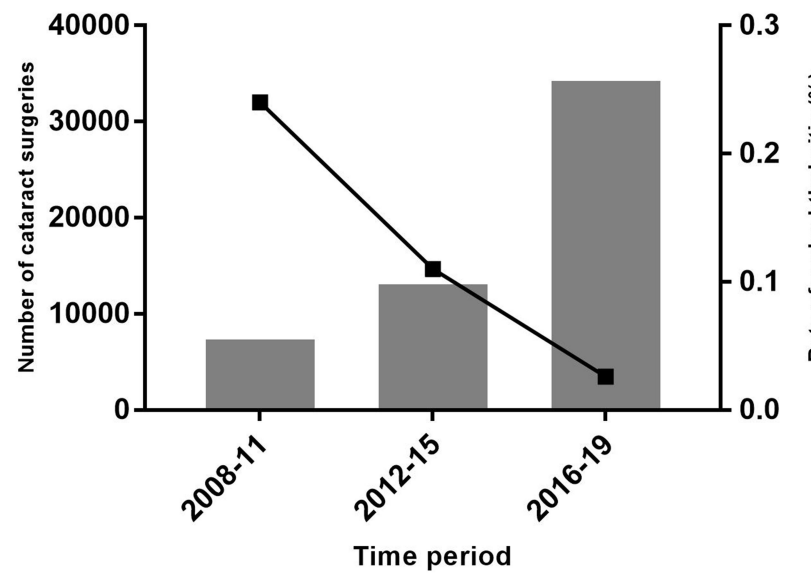

Figure 2 Trend chart of cataract surgery volume and incidence of postoperative infectious endophthalmitis in our hospital in recent 12 years.

rupture showed a downward trend (2008-2011, 131/7651, $1.71 \%$; 2012-2015, 203/13409, 1.51\%; 2016-2019, 37/ $34552,0.11 \%$ ). The incidence of infective endophthalmitis was negatively correlated with the integrity of posterior capsule $(\mathrm{P}<0.05)$. The intraoperative use of antibiotics and behind-the-lens washout were closely related to the occurrence of postoperative endophthalmitis $(\mathrm{P}<0.05)$. However, there was no significant difference in sex, age and history of diabetes $(\mathrm{P}>0.05)$ (Table 1$)$.

Multivariate logistic regression analysis was used to analyze the related factors of endophthalmitis. As a result, the protective factors were age, year of operation, use of antibiotics $(0<\mathrm{OR}<1)$, and the risk factor was posterior capsule rupture $(\mathrm{OR}>1)$. In the cases, we found that posterior capsule rupture was the main risk factor for endophthalmitis after cataract surgery, and intraoperative
Table I Univariate Analysis of Patients with Endophthalmitis After Cataract Surgery

\begin{tabular}{|c|c|c|c|}
\hline & $\begin{array}{c}\text { Number of } \\
\text { Endophthalmitis/ } \\
\text { Number of } \\
\text { Cataract } \\
\text { Surgery }\end{array}$ & $\begin{array}{l}\text { Incidence } \\
\text { Rate }\end{array}$ & P value* \\
\hline \multicolumn{4}{|l|}{ Year } \\
\hline 2008-20II & $|8 / 765|$ & $0.24 \%$ & 0.000 \\
\hline $2012-2015$ & $15 / 13,409$ & $0.11 \%$ & \\
\hline $2016-2019$ & $9 / 34,552$ & $0.026 \%$ & \\
\hline \multicolumn{4}{|l|}{ Gender } \\
\hline Male & $15 / 22,679$ & $0.066 \%$ & 0.532 \\
\hline Female & $27 / 32,933$ & $0.081 \%$ & \\
\hline \multicolumn{4}{|l|}{ Age (years) } \\
\hline$\leq 44$ & $3 / 156 \mid$ & $0.192 \%$ & 0.067 \\
\hline $45-59$ & 8/7891 & $0.101 \%$ & \\
\hline $60-74$ & $24 / 28,013$ & $0.085 \%$ & \\
\hline$\geq 75$ & $7 / 18,147$ & $0.038 \%$ & \\
\hline \multicolumn{4}{|l|}{ Diabetes } \\
\hline$Y$ & $8 / 10,306$ & $0.078 \%$ & 0.845 \\
\hline $\mathrm{N}$ & $34 / 45,306$ & $0.075 \%$ & \\
\hline \multicolumn{4}{|l|}{$\begin{array}{l}\text { Rupture of } \\
\text { posterior capsule }\end{array}$} \\
\hline$Y$ & $2 / 371$ & $0.539 \%$ & 0.032 \\
\hline $\mathrm{N}$ & $40 / 55,24 I$ & $0.072 \%$ & \\
\hline \multicolumn{4}{|l|}{ Antibiotic } \\
\hline$Y$ & 4/28,| & $0.014 \%$ & 0.000 \\
\hline$N$ & $38 / 27,44 I$ & $0.138 \%$ & \\
\hline \multicolumn{4}{|l|}{$\begin{array}{l}\text { Behind-the-lens } \\
\text { washout }\end{array}$} \\
\hline$Y$ & $9 / 34,552$ & $0.026 \%$ & 0.000 \\
\hline $\mathrm{N}$ & $33 / 21,060$ & $0.157 \%$ & \\
\hline
\end{tabular}

Notes: *Chi-square test was used for the factors of operation year and age, and Fisher test was used for sex, diabetes, rupture of posterior capsule, antibiotics and behind-the-lens washout factors.

Abbreviations: $\mathrm{Y}$, yes; $\mathrm{N}$, no.

use of antibiotics could prevent the occurrence of endophthalmitis. There was a certain correlation between the occurrence of endophthalmitis and the age of operation. In addition, the incidence of endophthalmitis was higher in young patients, and higher in young people than in the elderly (Table 1, Table 2).

The time of endophthalmitis after cataract surgery was 1-40 days, with an average of 10.57 days \pm 11.17 . According to the clinical manifestations of infective endophthalmitis, visual acuity decreased significantly in 16 patients $(38.1 \%)$ and eye pain in 25 patients $(59.5 \%)$. 
Table 2 Multivariate Logistic Regression Analysis of Endophthalmitis After Cataract Surgery

\begin{tabular}{|l|c|c|c|}
\hline Factors & OR & 95\% C.I. & P value* \\
\hline Rupture of posterior capsule & 3.861 & $0.922-16.162$ & 0.064 \\
Age & 0.696 & $0.487-0.997$ & 0.048 \\
Year & 0.521 & $0.318-0.853$ & 0.010 \\
Antibiotics & 0.316 & $0.100-1.004$ & $0.05 \mathrm{I}$ \\
\hline
\end{tabular}

Note: *Multivariate logistic regression analysis used for the factors of rupture of posterior capsule, age, year and antibiotics.

Slit-lamp examination found 31 patients (73.8\%) with fibrin exudation of anterior chamber and 8 patients $(19.0 \%)$ with hypopyon. In addition, inflammatory cells were found in the vitreous cavity of 18 patients $(42.9 \%)$ by fundus examination (Figure 3).

Among the 42 patients, 3 patients did not undergo laboratory examination because they had been treated with antibiotic via conjunctival sac, and the other 39 patients were examined by conjunctival sac or intraocular specimens. As a result, the results of anterior chamber fluid or vitreous fluid culture were positive in 10 patients, and negative in other cases. In addition, bacterial culture of conjunctival sac was performed in 31 patients with endophthalmitis, 12 of them $(38.7 \%)$ were positive, 8 cases $(8 / 12,66.7 \%)$ were Staphylococcus epidermidis, and others including 1 case of Acinetobacter baumannii, 1 case of Staphylococcus intermedia, 1 case of Staphylococcus aureus and 1 case of Staphylococcus haemolyticus. C-reactive protein test was performed in 23 patients $(23 / 42,54.8 \%)$, and there was no significant increase (Table 3 ).

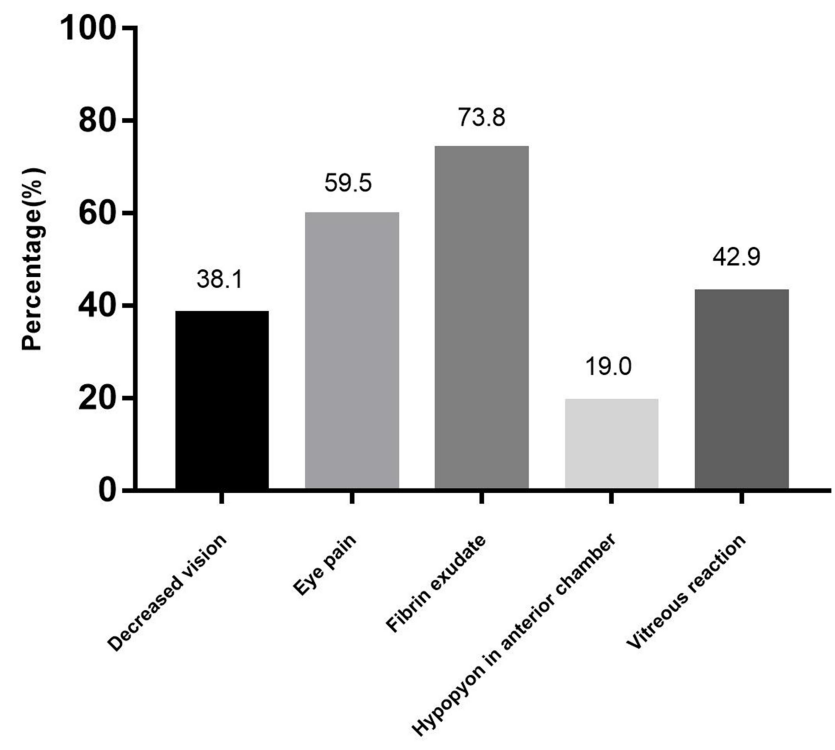

Figure 3 Clinical manifestations of endophthalmitis: a report of 42 cases.
Table 3 Results of Laboratory Bacterial Cultures of 42 Cases Intraocular Specimens of Endophthalmitis

\begin{tabular}{|l|l|l|}
\hline Species & No. & $\%$ \\
\hline Negative & 17 & 63.0 \\
Coagulase-negative Staphylococci & 1 & 3.7 \\
Staphylococcus aureus & 2 & 7.4 \\
Enterococci & 1 & 3.7 \\
Pseudomonas species & 1 & 3.7 \\
Streptococcus & 2 & 7.4 \\
Other gram-positive bacteria & 2 & 7.4 \\
Other gram-negative bacteria & 1 & 3.7 \\
Total & 27 & 100 \\
\hline
\end{tabular}

\section{Treatment and Prognosis}

According to the phased treatment plan, 15 cases $(35.7 \%)$ were treated with eye drops and systemic antibiotics, and 21 cases $(50 \%)$ were treated with antibiotics combined with anterior chamber lavage or vitreous injection of antibiotics. Vitrectomy combined with other methods was performed in six cases $(14.3 \%)$, of which two cases were treated with multiple anterior chamber lavage combined with vitreous cavity injection to treat intraocular inflammation without effective control. And we conducted vitrectomy combined with intraocular lens extraction (one case of anterior aqueous humor culture was aseptic, conjunctival sac culture was Staphylococcus epidermidis, one case of anterior chamber fluid and vitreous fluid culture was Enterococcus faecalis).

The visual acuity was counted by $\log$ MAR. The average visual acuity of endophthalmitis was $0.848 \pm 0.601$ at the time of endophthalmitis and $0.469 \pm 0.325$ after treatment. Except for patients with endophthalmitis after vitrectomy combined with intraocular lens extraction and without secondary intraocular lens suspension, the visual acuity of other patients after treatment was significantly higher than that of endophthalmitis $(\mathrm{P}<0.05)$. All patients had no serious complications such as eyeball enucleation, retinal detachment, corneal endothelial decompensation and secondary glaucoma.

\section{Discussion}

As one of the most intractable complications for cataract doctors, Infectious endophthalmitis after cataract extraction is extremely destructive to vision. In recent years, the incidence of endophthalmitis after cataract surgery in our hospital has changed As a consequence, we collected 55,612 cases of cataract extraction combined with intraocular lens implantation in our hospital in the past 12 years for retrospective analysis. 
The results showed that the incidence of endophthalmitis after cataract surgery in Qingdao Eye Hospital from 2008 to 2019 was $0.076 \%$, which was similar to the Chinese national-wide incidence of endophthalmitis in $2017 .^{6}$ The duration of the 12 years was divided into three stages to analyze the changes of its incidence and found the incidence of endophthalmitis in 2008-2011 was $0.24 \%, 0.11 \%$ in $2012-2015$, and $0.026 \%$ in 2016-2019. The incidence of endophthalmitis decreased significantly in the three periods of the 12 years, and it was significantly lower than $0.033 \%$ reported by large ophthalmology institutions in China in the past 3 years. It was similar to the results of $\mathrm{Oh}_{\text {et.al }}{ }^{7}$ about big data of cataract surgery in South Korea from 2002 to 2013.

Studies ${ }^{8,9}$ showed that eye pain and hypopyon occur in $75 \%$ of the clinical manifestations of endophthalmitis after cataract surgery, which was different from our clinical findings. In this study that the proportion of fibrin exudation of anterior chamber under slit lamp was $73.8 \%$, which was the main clinical manifestation of endophthalmitis in our hospital. It was considered that it was related to different infection flora, followed by eye pain $(59.5 \%)$. Only $19.0 \%$ of the cases showed hypopyon visible to the naked eye, but the presence of pus cells visible under microscope could not be ruled out. In two of the cases, purulent cells could be seen in the smears of the anterior chamber when the anterior chamber hypopyon was not seen with the slit lamp. In addition, the statistical results of 12 years in our hospital showed that the median time of occurrence and diagnosis of endophthalmitis after cataract surgery was 8 days, which was consistent with the results reported in the literature from 6 to 10 days after operation., ${ }^{2,10,11}$

Previous studies ${ }^{12}$ have shown that endophthalmitis after cataract surgery is mostly caused by normal ocular surface flora. Staphylococcus epidermidis is the normal flora of human skin, ocular surface and respiratory tract, which can cause infection of related parts under specific conditions, which was also consistent with the distribution characteristics of conjunctival sac pathogens in China. ${ }^{13}$ In this study, Staphylococcus epidermidis was the main pathogen in conjunctival culture of endophthalmitis patients (10/31). The positive rate of bacterial culture in aqueous humor and vitreous was $37 \%$ (10/27), which was similar to that of Yao et al. ${ }^{1}$ We found that bacteria were dispersed culture of 27 patients with endophthalmitis.

In this study, the rupture of posterior capsule, the use of antibiotics during operation and behind-the-lens washout were related to the occurrence of endophthalmitis after cataract surgery according to the statistical comparative study of various factors $(\mathrm{P}=0.032, \mathrm{P}=0.000, \mathrm{P}=0.000)$.

The rupture of lens posterior capsule is an important factor in endophthalmitis after cataract surgery. Moshirfar et $\mathrm{al}^{14}$ believed that rupture of the posterior capsule of the lens can lead to endophthalmitis in $0.07 \%$ of cases with no significant risk. In this study, the incidence of posterior capsule rupture was $0.667 \%(371 / 55,612)$, which was $4.761 \%(2 / 42)$ in endophthalmitis patients, and multivariate analysis showed that posterior capsule rupture was the main risk factor for endophthalmitis. With the modernization of ophthalmic instruments and the proficiency of minimally invasive surgery techniques of ophthalmic surgeons, the incidence of posterior capsule rupture in cataract surgery is decreasing year by year. However, it is still one of the main factors of endophthalmitis after cataract surgery. ${ }^{15-17}$ The intact posterior capsule is the anatomical barrier for microorganisms to enter the vitreous cavity, and the vitreous cavity is more vulnerable to bacteria than the anterior chamber. In addition, the treatment of complications will prolong the operation time such as vitreous prolapse and increase the risk of infectious endophthalmitis significantly. ${ }^{18}$

In recent years, cefuroxime sodium is used for patients without cephalosporin allergy in order to prevent endophthalmitis in cataract surgery of our hospital ${ }^{19}$ and the effect is remarkable. The European Association of Cataract and Refractive Surgeons (ESCR) study ${ }^{9}$ showed the incidence of endophthalmitis decreased by fivefold during cataract surgery using cefuroxime, while the latest study in $2015^{20}$ found that it could be reduced from $0.179 \%$ to $0.067 \%$. Intraoperative use of cefuroxime sodium can significantly reduce the infection rate of endophthalmitis dominated by gram-positive bacteria, but there is no difference on Gram-negative bacteria, which may be related to the weak effect of cefuroxime on Gramnegative bacteria. ${ }^{21}$ At present, the use of intraoperative antibiotics is still controversial. ${ }^{22-25}$ There are significant differences in the use of prophylactic antibiotics in cataract surgery in different countries due to the risks, such as wrong drug concentration, toxic and allergic reactions, and the lack of available, reasonable, safe and effective antibiotics in the market. Many studies ${ }^{26,27}$ have shown the effectiveness of cleaning conjunctival sac with povidone-iodine in the prevention of endophthalmitis, even in the replacement of antibiotics. ${ }^{7,28,29}$ All cataract patients in our hospital were disinfected with povidone-iodine 
conjunctival sac before operation during the period of this study. As a consequence, there was no correlation analysis in this study.

In this study, univariate analysis showed that behindthe-lens washout during cataract surgery had a significant effect on inhibiting the incidence of postoperative preventing endophthalmitis, which was consistent with the view of Oshika et al. ${ }^{30}$ In cataract extraction, it is necessary to remove the ophthalmic viscoelastic agent to prevent high intraocular pressure, but behind-the-lens washout can more sufficient to clean the surface of IOL, because studies $^{7,9,31-33}$ showed bacteria could adhere to the surface of ophthalmic instruments and IOL, increasing the risk of endophthalmitis, especially hydrophobic IOL.

In addition, studies ${ }^{34,35}$ showed that advanced age, history of diabetes and seasonal factors were also important risk factors of endophthalmitis after cataract surgery. The univariate analysis of the history of advanced age and diabetes mellitus in our study showed that it had no effect on the incidence of endophthalmitis $(\mathrm{P}=0.067, \mathrm{P}=0.845)$. However, the multifactor study found that the incidence of endophthalmitis in young patients after cataract surgery in our hospital was higher than that in elderly patients, which was related to the better compliance of elderly patients with postoperative medication. It could not be ruled out that as a tertiary ophthalmological hospital the patients having fewer basic diseases and better blood glucose control in elderly patients.

Some scholars believe that season ${ }^{13,36,37}$ and humidity and temperature $^{38}$ have an effect on the incidence of endophthalmitis after cataract surgery. The incidence of endophthalmitis in summer is higher than that in other seasons, and the incidence of endophthalmitis is high in hot and humid months. The incidence curve of endophthalmitis in different months in our study showed that the incidence of endophthalmitis was the highest in May and June. In addition, there was no abnormality in the detection of C-reactive protein in 23 patients with infective endophthalmitis in our hospital. Previous studies showed serological laboratory antibody detection cannot fully reflect intraocular infection. ${ }^{39}$ In patients with endogenous infective endophthalmitis, C-reactive protein increased significantly, ${ }^{40}$ but for less virulent pathogens, the increase of c-reactive protein was not significant. ${ }^{41}$

Although there are still potential confounding factors in the factors related to endophthalmitis, we believe that our data are reliable. In the 12 years involved in this study, the surgeons and operation environment were relatively stable, although the proportion of surgeons' operation volume changed; there was no significant technological change in cataract surgery, and behind-the-lens washout was the only technology adopted since 2016. In addition, from June 2018, the type of antibiotic eye drops was changed from $0.5 \%$ levofloxacin to $0.3 \%$ gatifloxacin according to the drug sensitivity test results of conjunctival sac bacteria. The impact of this change remains to be determined, but it was not included in the study due to the short time.

At present, the incidence of infective endophthalmitis after cataract extraction combined with intraocular lens implantation has been significantly reduced, but it is still one of the serious complications. In a word, reducing the probability of lens posterior capsule rupture, behind-the-lens washout and prophylactic use of antibiotics can effectively reduce the incidence of endophthalmitis after cataract extraction combined with intraocular lens implantation.

\section{Disclosure}

The authors report no conflicts of interest in this work.

\section{References}

1. Yao K, Zhu Y, Zhu Z, et al. The incidence of postoperative endophthalmitis after cataract surgery in China: a multicenter investigation of 2006-2011. Br J Ophthalmol. 2013;97(10):1312-1317. doi:10.1136/bjophthalmol-2013-303282

2. Friling E, Lundstrom M, Stenevi U, Montan P. Six-year incidence of endophthalmitis after cataract surgery: Swedish national study. $J$ Cataract Refract Surg. 2013;39(1):15-21. doi:10.1016/j. jers.2012.10.037

3. Schmier JK, Hulme-Lowe CK, Covert DW, Lau EC. An updated estimate of costs of endophthalmitis following cataract surgery among medicare patients: 2010-2014. Clin Ophthalmol. 2016;10:2121-2127. doi:10.2147/OPTH.S117958

4. Chiquet C, Boisset S, Pechinot A, et al. Massilia timonae as cause of chronic endophthalmitis following cataract surgery. $J$ Cataract Refract Surg. 2015;41(8):1778-1780. doi:10.1016/j.jcrs.2015.07.016

5. Matsuura K, Miyoshi T, Suto C, et al. Efficacy and safety of prophylactic intracameral moxifloxacin injection in Japan. $J$ Cataract Refract Surg. 2013;39(11):1702-1706. doi:10.1016/j.jcrs.2013.05.036

6. Zhu Y, Chen X, Chen P, et al. The occurrence rate of acute-onset postoperative endophthalmitis after cataract surgery in Chinese smalland medium-scale departments of ophthalmology. Sci Rep. 2017;7:40776. doi:10.1038/srep40776

7. Oh BL, Lee JS, Lee HY, Yu HG. Change in nationwide incidence of post-cataract surgery endophthalmitis: Korean cohort study from 2002 to 2013. Ocul Immunol Inflamm. 2019;27(5):756-761. doi:10.1080/ 09273948.2018.1484492

8. Endophthalmitis Vitrectomy Study Group. Results of the endophthalmitis vitrectomy study. A randomized trial of immediate vitrectomy and of intravenous antibiotics for the treatment of postoperative bacterial endophthalmitis. Arch Ophthalmol. 1995;113(12):1479-1496. doi:10.1001/archopht.1995.01100120009001

9. Endophthalmitis Study Group ESoC, Refractive S. Prophylaxis of postoperative endophthalmitis following cataract surgery: results of the ESCRS multicenter study and identification of risk factors. $J$ Cataract Refract Surg. 2007;33(6):978-988. doi:10.1016/j. jcrs.2007.02.032 
10. Jabbarvand M, Hashemian H, Khodaparast M, et al. Endophthalmitis occurring after cataract surgery: outcomes of more than 480000 cataract surgeries, epidemiologic features, and risk factors. Ophthalmology. 2016;123(2):295-301. doi:10.1016/j. ophtha.2015.08.023

11. Ledbetter EC, Spertus CB, Kurtzman RZ. Incidence and characteristics of acute-onset postoperative bacterial and sterile endophthalmitis in dogs following elective phacoemulsification: 1,447 cases (1995-2015). J Am Vet Med Assoc. 2018;253(2):201-208. doi:10.2460/javma.253.2.201

12. Blom K, Jorstad OK, Bragadottir R. Endophthalmitis in Oslo, Norway. Acta Ophthalmol. 2019;97(7):695-699. doi:10.1111/ aos. 14028

13. Huang Y, Zhan Y, Xie L. [Clinical observations of acute-onset endophthalmitis after clear corneal phacoemulsification]. Zhonghua Yan Ke Za Zhi. 2015;51(12):918-923. Chinese.

14. Moshirfar M, Feiz V, Vitale AT, et al. Endophthalmitis after uncomplicated cataract surgery with the use of fourth-generation fluoroquinolones: a retrospective observational case series. Ophthalmology. 2007;114(4):686-691. doi:10.1016/j.ophtha.2006.08.038

15. Wai YZ, Fiona Chew LM, Mohamad AS, et al. The Malaysian cataract surgery registry: incidence and risk factors of postoperative infectious endophthalmitis over a 7-year period. Int J Ophthalmol. 2018;11(10):1685-1690. doi:10.18240/ijo.2018.10.17

16. Day AC, Donachie PH, Sparrow JM, et al. The royal college of ophthalmologists' national ophthalmology database study of cataract surgery: report 1, visual outcomes and complications. Eye. 2015;29 (4):552-560. doi:10.1038/eye.2015.3

17. Creuzot-Garcher C, Benzenine E, Mariet AS, et al. Incidence of acute postoperative endophthalmitis after cataract surgery: a nationwide study in France from 2005 to 2014. Ophthalmology. 2016;123 (7):1414-1420. doi:10.1016/j.ophtha.2016.02.019

18. Lundstrom M, Wejde G, Stenevi U, et al. Endophthalmitis after cataract surgery: a nationwide prospective study evaluating incidence in relation to incision type and location. Ophthalmology. 2007;114 (5):866-870. doi:10.1016/j.ophtha.2006.11.025

19. Ma X, Xie L, Huang Y. Intraoperative cefuroxime irrigation prophylaxis for acute-onset endophthalmitis after phacoemulsification surgery. Infect Drug Resist. 2020;13:1455-1463. doi:10.2147/IDR. S252674

20. Javitt JC. Intracameral antibiotics reduce the risk of endophthalmitis after cataract surgery: does the preponderance of the evidence mandate a global change in practice? Ophthalmology. 2016;123 (2):226-231. doi:10.1016/j.ophtha.2015.12.011

21. O'Brien TP, Arshinoff SA, Mah FS. Perspectives on antibiotics for postoperative endophthalmitis prophylaxis: potential role of moxifloxacin. J Cataract Refract Surg. 2007;33(10):1790-1800. doi:10.1016/j.jcrs.2007.06.026

22. Sakarya Y, Sakarya R. Cefuroxime dilution error. Eur J Ophthalmol. 2010;20(2):460-461. doi:10.1177/112067211002000232

23. Svetozarskiy SN, Andreev AN. [Complications of intracameral cefuroxime in cataract surgery]. Vestn Oftalmol. 2018;134(5):104-110. doi:10.17116/oftalma2018134051104. Russian.

24. Moisseiev E, Levinger E. Anaphylactic reaction following intracameral cefuroxime injection during cataract surgery. J Cataract Refract Surg. 2013;39(9):1432-1434. doi:10.1016/j.jcrs.2013.06.008

25. Cakir B, Celik E, Aksoy NO, et al. Toxic anterior segment syndrome after uncomplicated cataract surgery possibly associated with intracamaral use of cefuroxime. Clin Ophthalmol. 2015;9:493-497. doi:10.2147/OPTH.S74249
26. Xia J, Lyons RJ, Lin MY, et al. Combination of lidocaine gel and povidone-iodine to decrease acquired infections in procedures performed using topical anesthesia. J Cataract Refract Surg. 2020;46 (7):1047-1050. doi:10.1097/j.jcrs.0000000000000245

27. Fan C, Yang B, Huang Y. Efficacy of $0.5 \%$ levofloxacin and 5.0\% povidone-iodine eyedrops in reducing conjunctival bacterial flora: metagenomic analysis. $J$ Ophthalmol. 2020;2020:1780498. doi:10.1155/2020/1780498

28. Moss JM, Sanislo SR, Ta CN. A prospective randomized evaluation of topical gatifloxacin on conjunctival flora in patients undergoing intravitreal injections. Ophthalmology. 2009;116(8):1498-1501. doi:10.1016/j.ophtha.2009.02.024

29. Matsuura K, Miyazaki D, Sasaki SI, et al. Effectiveness of intraoperative iodine in cataract surgery: cleanliness of the surgical field without preoperative topical antibiotics. Jpn J Ophthalmol. 2020;64 (1):37-44. doi:10.1007/s10384-019-00703-5

30. Oshika T, Ohashi Y. Endophthalmitis after cataract surgery: effect of behind-the-lens washout. J Cataract Refract Surg. 2017;43 (11):1399-1405. doi:10.1016/j.jcrs.2017.08.009

31. Suzuki T, Wada T, Kozai S, et al. Contribution of secreted proteases to the pathogenesis of postoperative Enterococcus faecalis endophthalmitis. J Cataract Refract Surg. 2008;34(10):1776-1784. doi:10.1016/j.jcrs.2008.06.033

32. Assia EI, Apple DJ, Lim ES, et al. Removal of viscoelastic materials after experimental cataract surgery in vitro. J Cataract Refract Surg. 1992;18(1):3-6. doi:10.1016/s0886-3350(13)80376-8

33. Baillif S, Ecochard R, Hartmann D, et al. [Intraocular lens and cataract surgery: comparison between bacterial adhesion and risk of postoperative endophthalmitis according to intraocular lens biomaterial]. J Fr Ophtalmol. 2009;32(7):515-528. doi:10.1016/j. jfo.2009.04.026.French.

34. Suto C, Morinaga M, Yagi T, et al. Conjunctival sac bacterial flora isolated prior to cataract surgery. Infect Drug Resist. 2012;5:37-41. doi:10.2147/IDR.S27937

35. Nowak MS, Grzybowski A, Michalska-Malecka K, et al. Incidence and characteristics of endophthalmitis after cataract surgery in Poland, during 2010-2015. Int J Environ Res Public Health. 2019;16(12):2188. doi:10.3390/ijerph16122188

36. $\mathrm{Kim} \mathrm{SH}, \mathrm{Yu} \mathrm{MH}$, Lee JH, et al. Seasonal variation in acute post-cataract surgery endophthalmitis incidences in South Korea. J Cataract Refract Surg. 2019;45(12):1711-1716. doi:10.1016/j. jcrs.2019.07.022

37. Rey JJ, Camacho PA, Serrano SE, et al. Confusion bias and seasonal variation of exogenous endophthalmitis incidence. J Cataract Refract Surg. 2020;46(3):491-492. doi:10.1097/j.jcrs.0000000000000091

38. Nam KY, Lee JE, Lee JE, et al. Clinical features of infectious endophthalmitis in South Korea: a five-year multicenter study. BMC Infect Dis. 2015;15:177. doi:10.1186/s12879-015-0900-5

39. Keorochana N, Intaraprasong W, Choontanom R. Herpesviridae prevalence in aqueous humor using PCR. Clin Ophthalmol. 2018;12:1707-1711. doi:10.2147/OPTH.S174694

40. Todokoro D, Mochizuki K, Nishida T, et al. Isolates and antibiotic susceptibilities of endogenous bacterial endophthalmitis: a retrospective multicenter study in Japan. J Infect Chemother. 2018;24(6):458-462. doi:10.1016/j.jiac.2018.01.019

41. Huber-Spitzy V, Arocker-Mettinger E, Herkner K, et al. Diagnosis and therapy of bacterial endophthalmitis, and serum levels of inflammation markers. Infection. 1992;20(3):122-127. doi:10.1007/ BF01704597 


\section{Publish your work in this journal}

Infection and Drug Resistance is an international, peer-reviewed openaccess journal that focuses on the optimal treatment of infection (bacterial, fungal and viral) and the development and institution of preventive strategies to minimize the development and spread of resistance. The journal is specifically concerned with the epidemiology of antibiotic resistance and the mechanisms of resistance development and diffusion in both hospitals and the community. The manuscript management system is completely online and includes a very quick and fair peerreview system, which is all easy to use. Visit http://www.dovepress.com/ testimonials.php to read real quotes from published authors. 